\title{
Client Perceptions of Quality and Choice at Static, Mobile Outreach, and Special Family Planning Day Services in 3 African Countries
}

\author{
Leah Jarvis, ${ }^{a}$ Jane Wickstrom, ${ }^{b}$ Caitlin Shannon ${ }^{c}$
}

In all 3 countries, nearly all women obtained their method of choice, with more mobile outreach and special family planning day clients having a preexisting preference for implants than static service clients. Clients of all service modalities in all countries reported experiencing most elements of full, free, and informed choice, but there is room for improvement with some aspects, such as counseling about potential side effects and giving clients the opportunity to ask questions.

Résumé en français à la fin de l'article.

\section{ABSTRACT}

Background: Use of long-acting reversible contraceptives (LARCs) has grown rapidly in the Democratic Republic of the Congo (DRC), Tanzania, and Uganda. Uptake of LARCs is particularly high during mobile outreach and special family planning day events. It is therefore important to examine client perceptions of and experiences with full, free, and informed choice (FFIC) in different service delivery modalities.

Methods: Between April and July 2015, we conducted a cross-sectional family planning client survey to assess FFIC and client satisfaction at static, mobile outreach, and special family planning day services in the DRC ( $n=9$ sites), Tanzania ( $n=13)$, and Uganda ( $n=8)$. The study investigated clients' perceptions across 13 elements of FFIC, including measures of the quality of counseling and respondent satisfaction with services across the service delivery approaches. Composite FFIC scores were constructed and analyzed as the proportion of women who reported affirmatively to all elements and the mean score of positive responses. Satisfaction was assessed using a 4-point Likert scale. We used logistic regression to assess the association between the primary outcomes and mode of service delivery.

Results: In total, we interviewed 585 women ( $\mathrm{n}=150$ in Uganda, $\mathrm{n}=200$ in Tanzania, and $\mathrm{n}=235$ in the DRC). The large majority of clients in all countries and modalities received their method of choice. Clients of mobile outreach and special family planning days preferred LARCs and permanent methods, particularly implants, compared with clients at static services. Composite measures of FFIC were lower for mobile outreach than for static services in Tanzania among all family planning clients (odds ratio $[O R]=0.5 ; P \leq .001$ ) and among LARC clients specifically (OR=0.5; $P \leq .01)$; no significant differences were found in the DRC or Uganda. A mean FFIC score among all family planning clients showed that clients in all modalities in all countries reported experiencing most elements of FFIC, with averages ranging from 4.8 to 6.1 of 7 elements. Among LARC clients specifically, mean scores ranged from 8.3 to 9.8 of 11 elements. Where greater proportions of clients experienced higher FFIC, greater proportions of clients also tended to report being "very satisfied" with aspects of services and counseling.

Conclusions: The results underscore that special family planning days and mobile outreach services are important and viable ways to increase women's access to family planning services, notably to LARCs, but further attention to respecting and fulfilling clients' full, free, and informed choice across all service delivery modalities is required.

\footnotetext{
a EngenderHealth, New York, NY, USA. Now with Population Council, New York, NY, USA.

${ }^{b}$ EngenderHealth, New York, NY, USA. Now with the Bill \& Melinda Gates Foundation, Seattle, WA, USA.

'EngenderHealth, New York, NY, USA.

Correspondence to Leah Jarvis (ljarvis@popcouncil.org).
}

\section{BACKGROUND}

n many sub-Saharan African countries, service delivery modalities such as mobile outreach services and special family planning days play an important role in increasing the use of modern contraception, especially underutilized, long-acting reversible contraceptives (LARCs) and permanent methods. ${ }^{1-7}$ 


\section{Non-static service delivery modalities, such as mobile outreach and special family planning days, increase access to family planning, especially to LARCs.}

\section{Following the 2012 London Summit, DRC, Tanzania, and Uganda set ambitious goals to increase the CPR and reduce unmet}

Mobile outreach services are crucial for increasing equitable access. By design, they serve poorer, marginalized, and geographically hardto-reach communities and populations. ${ }^{4,7-9}$ Such services are characterized by the deployment of trained providers to lower-level health facilities or temporary set-ups-such as tents or community spaces - that are equipped with the required contraceptives and supplies. ${ }^{6,7,9,10}$

Special family planning days are distinct events that are well-advertised in the community and organized at higher-level facilities during which a full range of contraceptive methods-including LARCs and, often, permanent methods-are available. Trained providers and counselors assemble in sufficient numbers to dedicate themselves to family planning for the day and plan to have sufficient stock on hand, thereby creating confidence in the community and among clients that family planning methods will be available.

Both of these non-static service delivery modalities increase access to family planning, especially to LARCs, for women who may not have routine access to a wide contraceptive method mix or to family planning at all. Although shortacting methods, such as hormonal injections and pills, are highly popular with family planning adopters in sub-Saharan Africa, studies show that when women are able to choose among a wide range of contraceptive options, significant proportions choose LARCs. ${ }^{1,5,9,11,12}$ Due in part to global investments since the 2012 London Summit for Family Planning, hormonal implants have become more available and, as a result, women are especially likely to select implants, as compared with other contraceptive methods, including intrauterine devices (IUDs), when they are available., 8,13-16 Although implants continue to represent a smaller proportion of the method mix in sub-Saharan Africa, they are one of the most rapidly growing contraceptive methods globally. ${ }^{12}$

EngenderHealth's Expand Family Planning (ExpandFP) Project (2013-2018), funded by the Bill \& Melinda Gates Foundation, aimed to increase contraceptive options, with a focus on LARCs, for women and girls in the Democratic Republic of the Congo (DRC), Tanzania, and Uganda. The project began shortly after the 3 countries set aggressive goals at the London Summit: the government of DRC committed to achieving a national contraceptive prevalence rate (CPR) of 19\% by 2020; Uganda's government committed to reducing unmet need to $10 \%$ by 2022; and Tanzania committed to doubling the number of family planning users to reach a national CPR of $60 \%$ by $2015 .^{17}$ Although
Tanzania did not achieve 60\% CPR within their stated time frame, the government recommitted to its family planning program, adding financial resources and a pledge to increase the availability of youth-friendly health services. ${ }^{18}$ All 3 countries recommitted to their family planning goals at the London Summit meeting in July 2017, adding pledges to protect, respect, and fulfill client rights to full, free, and informed contraceptive choice. ${ }^{19}$

As a result of public- and private-sector family planning initiatives supported by governments, donors, and technical assistance partners, significant progress has been made in family planning use overall, and in use of LARCs more specifically. For example, in Kinshasa, DRC, rates of LARC/ permanent method adoption increased quicklyfrom $2.5 \%$ prevalence in 2013 to $5.3 \%$ in 2015 as these methods became more available. ${ }^{20}$ In Uganda, the 2016 Demographic and Health Survey (DHS) showed that the overall CPR was increasing, with the prevalence of implant use among married women more than doubling in 5 years-from $2.7 \%$ in 2011 to $6.3 \%$ in 2016 and with IUDs remaining a much smaller proportion of the method mix, but still tripling from $0.5 \%$ to $1.5 \% .^{21,22}$ In Tanzania, the prevalence of implants nearly tripled among married women between the 2010 and 2015 DHS-from $2.3 \%$ to $6.7 \%$-though IUDs remained below $1.0 \% .^{23,24}$

In all 3 countries, EngenderHealth's program introduced a voluntary, human rights-based approach and framework at national and project implementation levels. The goal was to build provider awareness and capacity in voluntary family planning programming, including counseling, to ensure that clients were able to make full, free, and informed choices (FFIC) and that programs assured equity and quality in the provision of care. $^{25,26}$

Full choice is defined as access to the widest range of methods possible. To what degree that is possible may depend on what methods are approved for use at the national level and any constraints on the type of facility or cadre of provider. Free choice is a voluntary decision, without barriers or coercion, about whether to use family planning and, if so, which method to use. Informed choice is a decision based on complete, accurate, and unbiased information about family planning method options, including benefits, side effects, risks, and information about the correct use of the method chosen and the risks of family planning nonuse. ${ }^{27}$ The concepts of quality counseling and FFIC are interrelated and fall within a larger framework of client rights. The FFIC framework includes many elements of 
counseling quality, such as information on the array of contraceptive options available to the client and the benefits and side effects of each option, and how to discontinue use, when the client wants or needs to have an IUD or implant removed. However, FFIC goes beyond counseling quality and other measurement frameworks by assessing a client's ability to obtain her method of choice and by asking her who is primarily responsible for deciding whether to use family planning and which method. These specific elements of FFIC are influenced by factors that are external to provider counseling, such as method availability, cost of methods, and spousal influence.

To enhance FFIC, the ExpandFP Project invested resources into focusing on family planning clinical and counseling training for providers, facilitative supervision, infrastructure and contraceptive security improvements, community engagement, and advocacy. The project supported national trainers to train family planning providers on clinical contraceptive methods and rights-based counseling techniques. Trainings were followed by onsite provider follow up and coaching. Facilitative supervision was conducted at least twice a year in higher-level supported facilities where special family planning days occurred. The interventions supported service delivery for both short-acting (pills, injectables, and condoms) and long-acting methods (implants and IUDs). Permanent methods-male and female sterilization-were not offered at study facilities in the DRC but were available at most facilities in Tanzania and Uganda.

Project-supported public-sector special family planning days used community health workers, mass media, and dedicated family planning providers. In addition, the project-supported publicsector mobile outreach teams of dedicated family planning providers to serve lower-level facilities in remote areas with short-acting, long-acting, and sometimes permanent family planning methods. For both special family planning days and mobile outreach, community mobilizers were engaged to inform the community about upcoming events. Although special family planning days were conducted at facilities that generally had the most methods available, they frequently struggled with stock-outs and provider unavailability, while mobile outreach events typically occurred in smaller facilities that usually only had short-acting methods. In Tanzania and Uganda, all family planning methods were provided free to clients at public facilities at all times. In the DRC, family planning methods were only free to clients

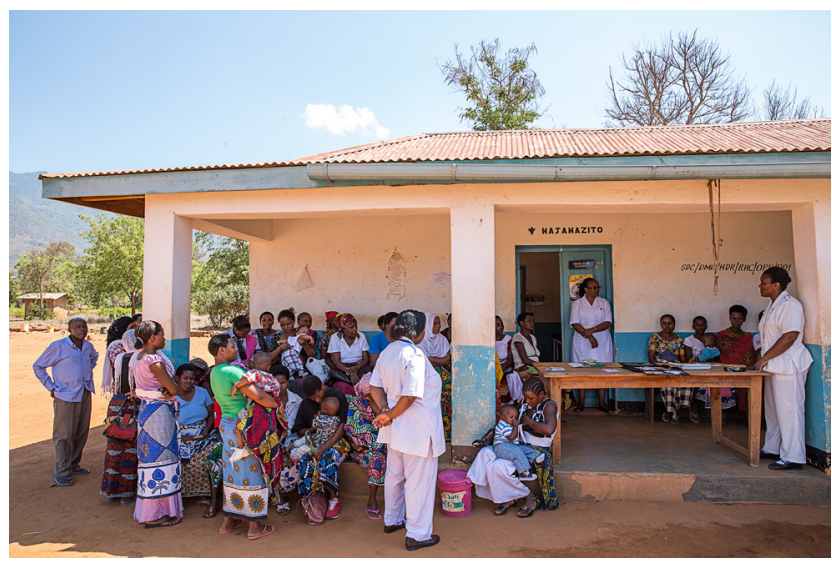

Clients of mobile outreach services in Tanzania listen to a group family planning counseling session. (c) 2015 Sala Lewis/EngenderHealth

during special family planning days and at mobile outreach events. Special family planning days and mobile outreach events served higher client loads than routine services in all 3 countries and were particularly high in the DRC and Tanzania. On average, for special family planning days, 97 clients were served per day in the DRC, 112 in Tanzania, and 33 in Uganda. On average, during mobile outreach events, an average of 60 clients were served per day in the DRC, 133 in Tanzania, and 23 in Uganda. During these events, clients obtained information both from group education/counseling sessions and from individual counseling with the provider.

With heightened awareness of FFIC and data showing significant increases in the number of hormonal implant adopters, especially in the DRC, government officials and program managers moved to increase their monitoring of FFIC, especially during high-volume mobile service delivery and special family planning day events. Steps to assess FFIC included improving supervision of counseling and conducting this study of client perceptions of quality and choice. ${ }^{28}$

This study investigated and compared aspects of FFIC and quality service delivery from the client perspective for routine static services, mobile outreach, and special family planning days. Our primary interest was to understand clients' experiences of FFIC and whether elements of FFIC varied by service delivery mode in project catchment areas. We also analyzed characteristics of the family planning clients to understand the populations reached by the 3 service delivery modalities in each country. This article adds to the literature

\author{
Special family \\ planning days \\ and mobile \\ outreach events \\ served higher \\ client loads than \\ routine services in \\ all 3 countries.
}


because previous studies have focused their research on FFIC and client satisfaction in private versus public clinics, ${ }^{29}$ the quality of mobile outreach services, ${ }^{3}$ and how client-centered counseling can improve client satisfaction. ${ }^{30,31}$ While many tools exist to aid programs in human-rights based programming and monitoring, they have seldom been brought to scale in national programs or measured systematically. ${ }^{32}$ This study goes beyond the current literature by comparing FFIC and client satisfaction among 3 service delivery modalities and underscoring the value of using existing tools to provide valuable monitoring data to inform program needs.

Answers from 13
indicators were
used to arrive at a
final composite
FFIC score to
measure clients'
positive
perceptions of and
satisfaction with
their service
delivery
experience.

METHODS

We conducted a cross-sectional, facility-based survey between April and July 2015 at 30 EngenderHealth supported-facilities: 9 in the DRC, 13 in Tanzania, and 8 in Uganda. In Tanzania and Uganda, the facilities selected were in peri-urban and rural areas, whereas in the DRC, the facilities were in peri-urban and urban areas of Kinshasa. The study purposefully selected facilities geographically spread across districts receiving support from EngenderHealth. Each data collection site had mobile, static, or in the DRC only, special family planning day services during the project period. Facilities were chosen for data collection by service delivery mode, based on the timing of family planning service activities, type of support from EngenderHealth (static and special family planning days vs mobile outreach), and expected client load. Some facilities had routine client loads too low to make reaching the desired sample feasible and, thus, were excluded. Facilities for mobile outreach collection were selected based on the scheduled mobile outreach activities during the data collection period.

Trained data collectors conducted exit interviews with clients immediately following their family planning visits. Clients were systematically sampled using an interval based on expected client load and were interviewed privately using a structured questionnaire. Signed informed consent was obtained in local languages prior to the interview. Eligible respondents were women aged 15 to 49 years seeking family planning services during static family planning service delivery or mobile outreach services (or in the case of the DRC only, during special family planning days), and who were not pregnant. Clients aged 15 to 17 years were eligible if they were legally emancipated. All data collectors were women to reduce respondent discomfort with questions related to reproductive behaviors and intentions.

\section{Outcomes}

The main outcomes assessed were measures of FFIC and client satisfaction.

Outcome indicators are defined in detail in Table 1. Indicators 1 through 13 directly correspond to responses to questions from client exit interviews that asked clients to report on the elements of counseling they received and their personal choice in method adoption. The majority of questions required a yes/no response: 1 recorded for a "yes" answer and 0 for "no." Indicators 1 and 2 were assessed among all respondents, indicators 3 through 9 among all respondents receiving a method, and indicators 3 through 13 among women who received a LARC. The proportion of positive responses were tabulated within the denominator category specified in Table 1.

To examine counseling and choice elements as a whole, not just individually, composite FFIC scores were constructed by summing the positive responses for indicators 3 through 9 for women receiving any method and summing positive responses from indicators 3 through 13 for women receiving a LARC method. FFIC scores were examined in 2 ways: (1) as a proportion of women who reported affirmatively to all elements in that category of user and (2) as a mean score of positive responses. The highest score possible for women receiving any method was 7 and the highest score for a woman receiving a LARC was 11 (Table 1 ).

We assessed satisfaction using a 4-point Likert scale: respondent was very dissatisfied, somewhat dissatisfied, somewhat satisfied, or very satisfied. Recognizing that courtesy bias contributes to high levels of satisfaction and that reporting "somewhat satisfied" versus "very satisfied" may indicate a small amount of dissatisfaction, we analyzed elements of satisfaction using a dichotomous variable categorized as "very satisfied" versus the rest.

Client characteristics assessed were reproductive intentions (i.e., desire to space or limit pregnancies), parity, marital status, age, education attained, and literacy as well as 2 proxy measures of socioeconomic status (SES): mobile phone ownership and home electricity. We also examined previous contraceptive use, method preference, and reproductive intentions as well as method received on the day of service. 
TABLE 1. Indicators of Full, Free, and Informed Choice and Rationale for Inclusion

\begin{tabular}{|c|c|c|}
\hline Indicator & Rationale & Denominator \\
\hline 1. Received an FP method & $\begin{array}{l}\text { Clients receiving FP is key to FFIC; however, a client not receiv- } \\
\text { ing a method does not necessarily demonstrate a lack of choice. } \\
\text { A client may come for removal, other services, or choose not to } \\
\text { adopt a method. }\end{array}$ & \multirow[t]{4}{*}{ All women } \\
\hline $\begin{array}{l}\text { 2. Reported being asked about reproductive } \\
\text { intentions (when or whether a client wants } \\
\text { more children) }\end{array}$ & $\begin{array}{l}\text { Provider's knowledge of a client's desire to delay, space, or } \\
\text { limit childbearing is important for recommending appropriate } \\
\text { methods. }\end{array}$ & \\
\hline $\begin{array}{l}\text { 3. Reported discussing } 3 \text { or more methods with } \\
\text { provider }\end{array}$ & $\begin{array}{l}\text { Clients should be aware that they have options to select the } \\
\text { method best suited for them. }\end{array}$ & \\
\hline 4. Client given a chance to ask questions & $\begin{array}{l}\text { Clients in any clinical setting should be given an opportunity to } \\
\text { ask questions. }\end{array}$ & \\
\hline 5. Obtained FP method of choice & $\begin{array}{l}\text { Full choice and free choice are contingent on the client receiving } \\
\text { her desired method. The reasons for not receiving the desired } \\
\text { method include unavailability of the method, lack of a trained } \\
\text { provider, cost, medical contraindication, or other. }\end{array}$ & \multirow[t]{5}{*}{$\begin{array}{l}\text { Women who } \\
\text { adopted an } \\
\text { FP method }\end{array}$} \\
\hline $\begin{array}{l}\text { 6. Participated in FP decision making (client } \\
\text { chose method by herself, jointly with the } \\
\text { provider, or jointly with a partner) }\end{array}$ & $\begin{array}{l}\text { Clients should have agency in choosing their method, either by } \\
\text { themselves or together with the provider, with a partner, or } \\
\text { with someone else. If the client reported that someone else } \\
\text { made the decision for her, a lack of FFIC is indicated. }\end{array}$ & \\
\hline 7. Counseled on method received & $\begin{array}{l}\text { The client being given general information on the method } \\
\text { received is key to being informed. }\end{array}$ & \\
\hline 8. Counseled on benefits of method received & $\begin{array}{l}\text { The client being told the benefits (e.g., effectiveness, health } \\
\text { benefits) of the method received is key to being informed. }\end{array}$ & \\
\hline $\begin{array}{l}\text { 9. Counseled on side effects of method } \\
\text { received }\end{array}$ & $\begin{array}{l}\text { The client being told and understanding the side effects of the } \\
\text { method received is key to being informed and can also prevent } \\
\text { early discontinuation. }\end{array}$ & \\
\hline 10. Told where to get implant/IUD removed & $\begin{array}{l}\text { A client should know the effort required to have the LARC } \\
\text { removed before she adopts it (e.g., long distance travel). }\end{array}$ & \multirow{4}{*}{$\begin{array}{l}\text { Women who } \\
\text { adopted a } \\
\text { LARC }\end{array}$} \\
\hline 11. Told when to get implant/IUD removed & $\begin{array}{l}\text { A client should know when to have the LARC removed. This is } \\
\text { key to correct use and fulfilling reproductive intentions. }\end{array}$ & \\
\hline $\begin{array}{l}\text { 12. Told could have implant/IUD removed } \\
\text { whenever she wanted }\end{array}$ & $\begin{array}{l}\text { A client should know that she is free to discontinue use when } \\
\text { desired. This is key to free choice. }\end{array}$ & \\
\hline $\begin{array}{l}\text { 13. Could correctly state the maximum duration } \\
\text { of implant/IUD use }\end{array}$ & $\begin{array}{l}\text { This indicator verified that clients understood the maximum } \\
\text { duration of use. }\end{array}$ & \\
\hline $\begin{array}{l}\text { FFIC composite: Percentage of FP adopters who } \\
\text { responded positively to indicators } 3 \text { through } 9\end{array}$ & $\begin{array}{l}\text { These } 7 \text { indicators represent the minimum threshold for a client } \\
\text { to fully exercise FFIC. All } 7 \text { indicators had to have a positive } \\
\text { response for this indicator to be satisfied. }\end{array}$ & \multirow[t]{2}{*}{$\begin{array}{l}\text { Women who } \\
\text { adopted an } \\
\text { FP method }\end{array}$} \\
\hline $\begin{array}{l}\text { FFIC score: Average number of indicators } 3 \\
\text { through } 9 \text { for which the response was positive } \\
\text { (maximum score of } 7 \text { ) }\end{array}$ & $\begin{array}{l}\text { The average provides a more nuanced view of the differences } \\
\text { among service-delivery approaches. }\end{array}$ & \\
\hline $\begin{array}{l}\text { FFIC LARC composite: Percentage of LARC } \\
\text { adopters who responded positively to indicators } \\
3 \text { through } 13\end{array}$ & $\begin{array}{l}\text { These } 11 \text { indicators represent the minimum threshold for a client } \\
\text { to fully exercise FFIC when obtaining a LARC: all regular indi- } \\
\text { cators of FFIC plus } 4 \text { specific to LARC. All } 11 \text { indicators had to } \\
\text { have a positive response for this indicator to be satisfied. }\end{array}$ & \multirow[t]{2}{*}{$\begin{array}{l}\text { Women who } \\
\text { adopted a } \\
\text { LARC }\end{array}$} \\
\hline $\begin{array}{l}\text { FFIC LARC score: Average number of indicators } \\
3 \text { through } 13 \text { for which the response was posi- } \\
\text { tive (maximum score of } 11 \text { ) }\end{array}$ & $\begin{array}{l}\text { The average score provides a more nuanced view of the dif- } \\
\text { ferences among service delivery approaches. }\end{array}$ & \\
\hline
\end{tabular}

Abbreviations: FFIC, full, free, and informed choice; FP, family planning; IUD, intrauterine device; LARC, long-acting reversible contraception. 


\section{Sample Size}

The sample size was estimated using client satisfaction as the key outcome of interest. Although satisfaction is not an ideal measure because of the potential for courtesy bias and subjectivity as an indicator of perceived quality of service delivery, ${ }^{14,16,17}$ it was one of the only measures we could estimate in advance with relative confidence to calculate sample size. Assuming that approximately $95 \%$ of clients would be somewhat or very satisfied, a sample of 73 was adequate at the $95 \%$ confidence level to assess client satisfaction at the service modality level. Historical service statistics helped determine an appropriate sampling interval by facility and service delivery modality in order to reach desired sample size using systematic sampling, with a minimum of 73 per service delivery modality. The desired sample was then divided across facilities participating in project-supported mobile outreach or special family planning days during the data collection period.

\section{Data Analysis}

Trained data clerks entered data using the Census and Survey Processing System (U.S. Census Bureau and ICF International, Washington DC, USA) data processing software package and cleaned and analyzed the data using Stata version 13 (StataCorp, College Station, TX, USA). We summarized client characteristics using means or medians for continuous variables and proportions for dichotomous variables. We also compared the characteristics of mobile outreach service attendees (and in the case of the DRC, special family planning days) against static service clients through 1-way measures of association: $t$ tests for continuous variables, such as age, and chi-square tests for categorical outcomes. To assess the association between each of the primary outcomes1 through 13 in Table 1, the FFIC composite statistics, and client satisfaction-with mode of service delivery (static or non-static) we used logistic regression. Mode of service delivery was the only predictive variable included in the models. We did not adjust for client characteristics, because client characteristics, such as age, marital status, education, and socioeconomic status, should not affect counseling practices or FFIC. Mean FFIC scores were compared using ANOVA instead of logistic regression. In the DRC, special family planning days and mobile outreach were combined into a single group because they are both nonstatic, high-volume modes of service delivery supported with many of the same program inputs and have similar client profiles for those attending events. Standard errors for each estimate presented were adjusted for by clustering by facility, the primary sampling unit. Only adjusted estimates are reported; all $P$ values reported are 2-sided; and differences in statistical significance at the $P \leq .05, P \leq .01$, and $P \leq .001$ were noted.

\section{Ethical Approvals}

The research protocol and materials were reviewed and approved by the Western International Review Board in the United States, the National Institute for Medical Research in Tanzania, the Research Ethics Committee of Makerere University in Uganda, and the Ethical Committee of the Public Health School of Kinshasa in the DRC.

\section{RESULTS}

A total of 614 women were screened for inclusion, of whom 596 were eligible; 587 consented to be interviewed; and 585 women completed the interview. Data were collected from 150 respondents in Uganda (90 static; 60 mobile outreach); 200 respondents in Tanzania (100 static; 100 mobile outreach); and 235 respondents in the DRC ( 55 static; 120 mobile outreach; 60 special family planning days). A smaller than anticipated client flow at static services in the DRC posed challenges for data collection, and timing and budgetary constraints resulted in a smaller than planned sample in family planning days in the DRC and mobile outreach in Uganda.

\section{Client Characteristics}

Client characteristics varied by mode of service delivery in the DRC. Overall, women seeking family planning at mobile outreach and special family planning days were similar to each other; however, compared with clients attending static services, they had less education, money, and history of family planning use and were more likely to have a preexisting preference for implants. Women at mobile outreach and special family planning days were less literate compared with women at static services $(60.8 \%, P \leq .01$, and $63.3 \%, P \leq .05$, respectively, compared with $83.3 \%$ ), and less likely to own a mobile phone (46.7\%, $P \leq .001$, and $56.7 \%, P \leq .05$, respectively, compared with $74.6 \%$ ) (Table 2 ). In terms of contraceptive history, women attending mobile outreach services and special family planning days had similar levels of modern method use, which were significantly lower than women attending 
TABLE 2. Profile of Family Planning Users by Country and Service Delivery Modality

\begin{tabular}{|c|c|c|c|c|c|c|c|}
\hline & \multicolumn{3}{|c|}{$\mathrm{DRC}(\mathrm{N}=235)^{\mathrm{a}}$} & \multicolumn{2}{|c|}{ Tanzania $(\mathrm{N}=200)$} & \multicolumn{2}{|c|}{ Uganda ( $\mathrm{N}=150)$} \\
\hline & $\begin{array}{l}\text { Static } \\
n=55\end{array}$ & $\begin{array}{l}\text { Outreach } \\
n=120\end{array}$ & $\begin{array}{l}\text { FP Day } \\
n=60\end{array}$ & $\begin{array}{l}\text { Static } \\
n=100\end{array}$ & $\begin{array}{l}\text { Outreach } \\
n=100\end{array}$ & $\begin{array}{l}\text { Static } \\
n=90\end{array}$ & $\begin{array}{l}\text { Outreach } \\
n=60\end{array}$ \\
\hline \multicolumn{8}{|l|}{ Age } \\
\hline Age, years, mean & 29.2 & $26.9 * b$ & $28.9^{* c}$ & 27.6 & 28.8 & 26.9 & 27.9 \\
\hline Age, years, range & $19-49$ & $17-45$ & $18-44$ & $18-49$ & $17-46$ & $17-47$ & $17-41$ \\
\hline \multicolumn{8}{|l|}{ Age groups, years, $\%$} \\
\hline $15-19$ & 1.8 & $11 . \%$ & 5.0 & 5.0 & 11.0 & 11.1 & 5.0 \\
\hline $20-24$ & 25.5 & 30.0 & 18.3 & 41.0 & 26.0 & 28.9 & 23.2 \\
\hline $25-29$ & 29.1 & 22.5 & 35.0 & 17.0 & 19.0 & 26.7 & 33.3 \\
\hline $30-34$ & 16.4 & 24.2 & 23.3 & 19.0 & 13.0 & 16.7 & 23.3 \\
\hline $35-39$ & 23.6 & 9.2 & 10.0 & 8.0 & 20.0 & 14.4 & 11.7 \\
\hline$\geq 40$ & 3.6 & 2.5 & 8.3 & 10.0 & 11.0 & 2.2 & 3.3 \\
\hline \multicolumn{8}{|l|}{ Marital Status } \\
\hline Married or in union, $\%$ & 81.8 & 68.3 & 81.7 & 84.0 & 82.0 & 80.0 & $93.3^{*}$ \\
\hline \multicolumn{8}{|l|}{ No. of Children } \\
\hline No. of children, mean & 3.8 & 4.1 & 4.1 & 2.8 & 3.4 & 3.3 & $4.1^{*}$ \\
\hline No. of children, range & $1-10$ & $0-10$ & $1-9$ & $0-11$ & $0-11$ & $0-9$ & $0-11$ \\
\hline \multicolumn{8}{|l|}{ No. of children, distribution, $\%$} \\
\hline $0-3$ & 49.1 & 44.2 & 38.3 & 76.0 & $62.0^{*}$ & 54.3 & 43.3 \\
\hline$>3$ & 50.9 & 55.8 & 61.7 & 24.0 & $38.0^{*}$ & 45.6 & 56.7 \\
\hline \multicolumn{8}{|l|}{ Education } \\
\hline Received at least some secondary education, \% & 83.6 & 75.0 & 75.0 & $25.0 \%$ & 15.0 & 31.1 & 25.0 \\
\hline Read some/all sample sentence, ${ }^{e} \%$ & 83.3 & $60.8^{* * b}$ & $63.3^{* d}$ & 85.0 & 83.0 & 80.0 & 75.0 \\
\hline \multicolumn{8}{|l|}{ Socioeconomic Status } \\
\hline Owns a mobile phone, $\%$ & 74.6 & $46.7^{* * * b}$ & $56.7^{* d}$ & 59.0 & $38.0^{* *}$ & 63.3 & 58.3 \\
\hline Has electricity, \% & 87.3 & 82.5 & $63.3^{* * c, d}$ & 26.0 & 24.0 & 30.0 & 25.0 \\
\hline \multicolumn{8}{|l|}{ Occupation $^{f}$} \\
\hline Housewife/not working, $\%$ & 27.3 & 40.8 & 41.7 & 16.0 & 12.0 & 18.9 & 13.3 \\
\hline Farmer, \% & 1.8 & 2.5 & 3.3 & 59.0 & $82.0^{* * *}$ & 55.6 & 65.0 \\
\hline Trader/business owner, $\%$ & 47.3 & 43.3 & 43.3 & 15.0 & $2.0^{* * *}$ & 20.0 & 15.0 \\
\hline \multicolumn{8}{|l|}{ Contraceptive History } \\
\hline Ever used modern FP, \% & 81.8 & $66.7^{* b}$ & $65.0^{* d}$ & 91.0 & 90.0 & 98.9 & 100.0 \\
\hline Ever used non-condom modern FP, \% & 74.6 & $46.7^{* * * b}$ & $51.7^{* d}$ & 83.0 & 84.0 & 88.9 & 96.7 \\
\hline Ever used LA/PM, \% & 5.5 & 2.5 & 3.3 & 33.0 & 36.0 & 25.6 & 15.0 \\
\hline \multicolumn{8}{|l|}{ Method Preferences } \\
\hline Had a preference for implant, \% & 58.2 & $86.7^{* * * \mathrm{~b}}$ & $85.0^{* * * d}$ & 41.0 & 55.0 & 25.6 & $51.7^{* * *}$ \\
\hline Had a preference for LA/PM, \% & 58.2 & $86.7^{* * * b}$ & $88.3^{* * * d}$ & 47.0 & $62.0^{*}$ & 28.9 & $53.3^{* *}$ \\
\hline Had a preference for short-acting method, $\%$ & 29.1 & $2.5^{* * * b}$ & $6.7^{* * d}$ & 37.0 & $20.0^{* *}$ & 63.3 & $33.3^{* * *}$ \\
\hline
\end{tabular}


TABLE 2. Continued

\begin{tabular}{|c|c|c|c|c|c|c|c|}
\hline & \multicolumn{3}{|c|}{$\mathrm{DRC}(\mathrm{N}=235)^{\mathrm{a}}$} & \multicolumn{2}{|c|}{ Tanzania $(\mathrm{N}=200)$} & \multicolumn{2}{|c|}{ Uganda $(\mathrm{N}=150)$} \\
\hline & $\begin{array}{l}\text { Static } \\
\mathrm{n}=55\end{array}$ & $\begin{array}{l}\text { Outreach } \\
n=120\end{array}$ & $\begin{array}{l}\text { FP Day } \\
n=60\end{array}$ & $\begin{array}{l}\text { Static } \\
n=100\end{array}$ & $\begin{array}{l}\text { Outreach } \\
n=100\end{array}$ & $\begin{array}{l}\text { Static } \\
\mathrm{n}=90\end{array}$ & $\begin{array}{l}\text { Outreach } \\
n=60\end{array}$ \\
\hline \multicolumn{8}{|l|}{ Fertility Desires } \\
\hline Wants no more children, $\%$ & 34.6 & 41.7 & 30.0 & 14.0 & $32.0^{* *}$ & 25.6 & $41.7^{*}$ \\
\hline Wants child 2 or more years, $\%$ & 49.1 & 40.0 & 50.0 & 67.0 & 55.0 & 44.4 & 38.3 \\
\hline Doesn't know when or if want more, $\%$ & 9.1 & 10.0 & 16.7 & 14.0 & 3.0 & 5.6 & 6.7 \\
\hline
\end{tabular}

Abbreviations: DRC, Democratic Republic of the Congo; FP, family planning; LA/PM, long-acting or permanent method.

a One-way analyses of statistical significance were conducted between mobile outreach and static services; special family planning days and static services; and special family planning days and mobile outreach.

${ }^{b}$ Difference between mobile outreach and static services was statistically significant

cDifference between special family planning days and mobile outreach was statistically significant.

dDifference between special family planning days and static services was statistically significant.

e Women who were visually impaired or who did not read the language on the card ( $n=5)$ were excluded.

${ }^{f}$ Only the 3 most common occupations overall are listed, so categories do not add up to $100 \%$.

${ }^{*} P \leq .05 ;{ }^{* *} P \leq .01 ;{ }^{* *} P \leq .001$

static services $(66.7 \%$ and $65.0 \%$, respectively, compared with $81.8 \%, P \leq .05)$. For both mobile outreach and special family planning days, clients preferred LARCs/permanent methods, and implants in particular, with $86.7 \%$ at mobile outreach services $(P \leq .001)$ and $85.0 \%$ at special family planning days $(P \leq .001)$ favoring the implant, compared with $58.2 \%$ of clients at static services. The only significant differences between clients attending mobile outreach services and clients at special family planning days were that the women attending special family planning

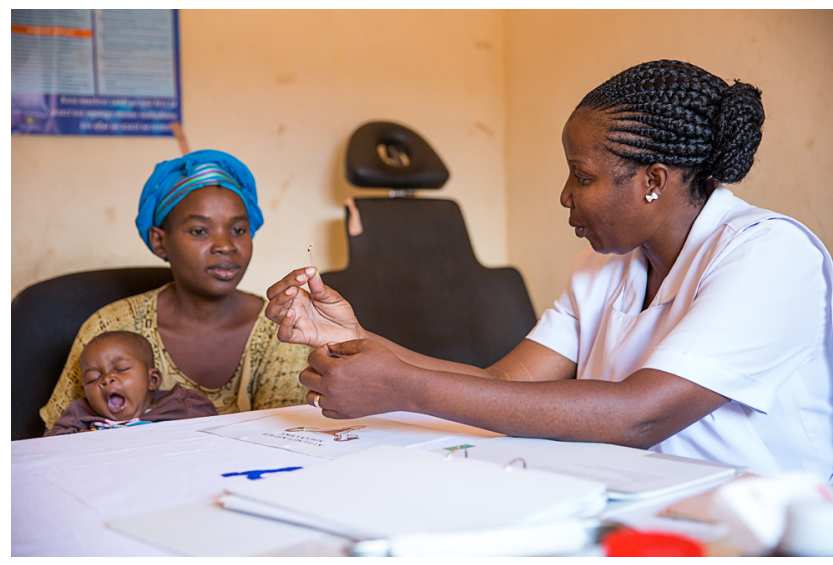

A family planning provider in Tanzania counsels a client of mobile outreach services on IUDs. (C) 2015 Sala Lewis/EngenderHealth days were older (28.9 years compared with 26.9 years, $P \leq .05$ ) and less likely to have electricity than mobile outreach clients $(63.3 \%$ compared with $82.5 \%, P \leq .01)$.

In Tanzania, women attending mobile outreach were more likely to have 3 or more children (38.0\% compared with $24.0 \%, P \leq .05$ ), were less likely to own a mobile phone $(38.0 \%$ compared with $59.0 \%, P \leq .01)$, and were more likely to be farmers $(82.0 \%$ compared with $59.0 \%, P \leq .001)$ than women at static services (Table 2). Although preference for an implant was not as pronounced as in the DRC, there was a clear preference for LARCs/permanent methods among mobile outreach clients compared with static service clients (62.0\% compared with $47.0 \%, P \leq .05)$. The women's reproductive intentions also varied, with $32.0 \%$ attending mobile outreach indicating that they wanted no more children compared with $14.0 \%$ at static services $(P \leq .01)$.

There were fewer differences between users of static and mobile outreach services in Uganda than in Tanzania and the DRC; however, differences did emerge. Women attending mobile outreach were more likely to be married or in union (93.3\% compared with $80.0 \%, P \leq .05)$, had a higher mean number of children $(4.1$ compared with 3.3, $P \leq .05)$, had a stronger preference for implants $(51.7 \%$ compared with $25.6 \%, P \leq .001)$, and had a greater desire to have no more children (41.7\% compared with $25.6 \%, P \leq .05$ ) compared with women attending static services (Table 2 ). 
TABLE 3. Primary Family Planning Method Received, by Country and Service Delivery Approach

\begin{tabular}{|c|c|c|c|c|c|c|c|}
\hline \multirow[b]{2}{*}{ Method } & \multicolumn{3}{|c|}{$\mathrm{DRC}(\mathrm{N}=235)^{\mathrm{a}}$} & \multicolumn{2}{|c|}{ Tanzania (N=200) } & \multicolumn{2}{|c|}{ Uganda ( $N=150)$} \\
\hline & $\begin{array}{l}\text { Static (\%) } \\
n=55\end{array}$ & $\begin{array}{l}\text { Outreach (\%) } \\
n=120\end{array}$ & $\begin{array}{l}\text { FP Day (\%) } \\
\mathrm{n}=60\end{array}$ & $\begin{array}{l}\text { Static (\%) } \\
n=100\end{array}$ & $\begin{array}{l}\text { Outreach (\%) } \\
n=100\end{array}$ & $\begin{array}{l}\text { Static (\%) } \\
n=90\end{array}$ & $\begin{array}{l}\text { Outreach (\%) } \\
n=60\end{array}$ \\
\hline No method & 5.5 & 2.5 & 0.0 & 6.0 & 9.0 & 8.9 & 18.3 \\
\hline Condom & 0.0 & 0.0 & 0.0 & 3.0 & 1.0 & 2.2 & 0.0 \\
\hline Pill & 1.8 & 0.0 & 0.0 & 13.0 & 9.0 & 11.1 & 11.7 \\
\hline Injectable & 29.1 & $3.3^{* * * b}$ & $1.7^{* * * c}$ & 24.0 & $8.0^{* *}$ & 51.1 & $23.3^{* *}$ \\
\hline Implant & 63.4 & $94.2^{* * * b}$ & $96.7^{* * * c}$ & 46.0 & $64.0^{* *}$ & 24.4 & $43.3^{*}$ \\
\hline IUD & 0.0 & 0.0 & 1.7 & 8.0 & 4.0 & 2.2 & 3.3 \\
\hline Tubal ligation & 0.0 & 0.0 & 0.0 & 0.0 & $5.0^{*}$ & 0.0 & 0.0 \\
\hline
\end{tabular}

Abbreviations: DRC, Democratic Republic of the Congo; FP, family planning; IUD, intrauterine device.

*P $\leq .05 ;{ }^{* *} P \leq .01 ;{ }^{* * *} P \leq .001$.

a One-way analyses of statistical significance were conducted between mobile outreach and static services, special family planning days and static services, and family planning days and mobile outreach.

${ }^{b}$ Difference between mobile outreach and static services was statistically significant.

cDifference between special family planning days and static services was statistically significant.

\section{Method Adoption}

In all countries, women's preference for LARC/ permanent methods, and especially for implants, was reflected in the method adopted (Table 3). Significantly higher percentages of women attending non-static services in the 3 countries adopted an implant and significantly lower percentages adopted an injectable compared with women at static services. Few clients in any modality adopted IUDs, condoms, or pills, although all of these methods were available at all service modalities. In the DRC, $63.4 \%$ of women attending static services adopted implants and $29.1 \%$ adopted injectables. In contrast, $94.2 \%$ of women attending mobile outreach and $96.7 \%$ at family planning day events adopted implants (both $P \leq .001$ ), whereas only $3.3 \%$ and $1.7 \%$ adopted injectables, respectively (both $P \leq .001$ ). In Tanzania, $64.0 \%$ of women attending mobile outreach adopted an implant compared with $46.0 \%$ at static services $(P \leq .01)$, and only $8.0 \%$ attending mobile outreach adopted an injectable compared with $24.0 \%$ at static services $(P \leq .01)$. Finally, in Uganda, $43.3 \%$ of women attending mobile outreach adopted an implant and $23.3 \%$ adopted an injectable compared with $24.4 \%$ adopting an implant $(P \leq .05)$ and $51.1 \%$ adopting an injectable $(P \leq .01)$ at static sites. The implant was the method most often adopted in each country and at each service delivery modality, with the exception of Uganda, where slightly more than half $(51.1 \%)$ of the clients attending static services chose an injectable.

\section{Composite and Individual Measures of FFIC}

Several significant differences were found in elements of FFIC between service delivery modalities in each country. The FFIC composite indicator for all clients adopting family planning showed that fewer than half the clients in any country or for any service delivery modality reported experiencing all aspects of FFIC (range, $19.2 \%$ to $48.1 \%$ ) (Table 4 ). Differences between service delivery modalities were significant only in Tanzania, where $31.9 \%$ of clients attending mobile outreach services reported experiencing all elements of FFIC compared with $48.9 \%$ of clients of static services (odds ratio $[\mathrm{OR}]=0.5$; $95 \%$ confidence interval [CI], 0.4 to $0.7 ; P \leq .001$ ). The trend was the same in the DRC, although the results were not significant. In all 3 countries, the average number of FFIC elements for which the response was positive (FFIC mean score) was between 4.8 and 6.1 (of 7). In Tanzania, women in static services reported experiencing on average 6.1 elements of FFIC compared with 5.6 in mobile outreach $(P=.02)$; no other significant differences were found. When looking exclusively at LARC adopters, differences between service modalities were significant only in Tanzania: $26.4 \%$ of clients of mobile outreach services reported experienc- 
TABLE 4. Measures of the Association of Service Delivery Approach With Elements of FFIC, by Country

\begin{tabular}{|c|c|c|c|c|c|c|c|c|c|}
\hline \multirow[b]{2}{*}{ Outcome } & \multicolumn{3}{|c|}{ DRC $(\mathrm{N}=235)$} & \multicolumn{3}{|c|}{ Tanzania (N=200) } & \multicolumn{3}{|c|}{ Uganda $(\mathrm{N}=150)$} \\
\hline & $\begin{array}{l}\text { Static } \\
\text { (n=55) } \\
\%\end{array}$ & $\begin{array}{l}\text { Outreach/ } \\
\text { Special FP Day } \\
(n=180) \\
\%\end{array}$ & $\begin{array}{l}\text { OR }(95 \% \mathrm{Cl})^{a} \\
\text { or } P \text { Value }\end{array}$ & $\begin{array}{l}\text { Static } \\
\text { (n=100) } \\
\%\end{array}$ & $\begin{array}{l}\text { Outreach } \\
(n=100) \\
\%\end{array}$ & $\begin{array}{l}\text { OR } \\
(95 \% \mathrm{Cl})^{\mathrm{a}}\end{array}$ & $\begin{array}{l}\text { Static } \\
\text { (n=90) } \\
\%\end{array}$ & $\begin{array}{l}\text { Outreach } \\
(n=60) \\
\%\end{array}$ & $\begin{array}{l}\text { OR }(95 \% \mathrm{Cl})^{\mathrm{a}} \\
\text { or } P \text { Value }{ }^{\mathrm{b}}\end{array}$ \\
\hline \multicolumn{10}{|l|}{ All women } \\
\hline 1. Obtained a method & 94.6 & 98.3 & $3.4(0.4,27.9)$ & 94.0 & 91.0 & $0.6(0.1,5.9)$ & 91.1 & 81.7 & $0.4(0.1,2.3)$ \\
\hline $\begin{array}{l}\text { 2. Reported being asked about } \\
\text { reproductive intentions }\end{array}$ & 80.0 & 59.4 & $0.4(0.1,2.7)$ & 94.0 & 75.0 & $0.2(0.1,0.7)^{* *}$ & 64.4 & 55.0 & $0.7(0.4,1.3)$ \\
\hline $\begin{array}{l}\text { 3. Reported discussing three or } \\
\text { more methods with provider }\end{array}$ & 65.5 & 78.3 & $1.9(0.4,10.1)$ & 90.0 & 81.0 & $0.5(0.2,1.1)$ & 26.7 & 41.7 & $2.0(0.3,12.5)$ \\
\hline 4. Given a chance to ask questions & 61.8 & 48.3 & $0.6(0.1,2.4)$ & 72.0 & 70.0 & $0.9(0.7,1.2)$ & 75.6 & 96.7 & $9.4(0.8,115.2)$ \\
\hline $\begin{array}{l}\text { Women who adopted an FP } \\
\text { method }\end{array}$ & $\mathrm{n}=52$ & $\mathrm{n}=177$ & & $n=94$ & $n=91$ & & $\mathrm{n}=82$ & $n=49$ & \\
\hline 5. Obtained FP method of choice & 100.0 & 98.3 & NA & 92.6 & 96.7 & $2.4(0.2,24.7)$ & 97.6 & 95.9 & $0.6(0.1,2.6)$ \\
\hline $\begin{array}{l}\text { 6. Participated in FP decision } \\
\text { making }\end{array}$ & 96.2 & 74.0 & $0.1(0.0,0.4)^{* * *}$ & 97.9 & 87.9 & $0.2(0.0,2.3)$ & 92.7 & 89.8 & $0.7(0.4,1.4)$ \\
\hline 7. Counseled on method received & 80.8 & 83.6 & $1.2(0.2,8.7)$ & 93.6 & 87.9 & $0.5(0.4,0.6)^{* * *}$ & 39.0 & 42.9 & $1.2(0.2,6.1)$ \\
\hline $\begin{array}{l}\text { 8. Counseled on benefits of method } \\
\text { received }\end{array}$ & 69.2 & 75.1 & $1.4(0.3,6.6)$ & 84.0 & 78.0 & $0.7(0.4,1.1)$ & 76.8 & 85.7 & $1.8(0.6,5.4)$ \\
\hline $\begin{array}{l}\text { 9. Counseled on side effects of } \\
\text { method received }\end{array}$ & 69.2 & 62.7 & $0.7(0.2,3.2)$ & 75.5 & 58.2 & $0.5(0.2,1.1)$ & 63.4 & 65.3 & $1.1(0.6,1.9)$ \\
\hline $\begin{array}{l}\text { FFIC composite: Percentage of } \\
\text { women who adopted an FP } \\
\text { method responding positively to } \\
\text { ALL indicators } 3 \text { through } 9\end{array}$ & 48.1 & 19.2 & $0.3(0.1,1.3)$ & 48.9 & 31.9 & $0.5(0.4,0.7)^{* * *}$ & 22.0 & 20.4 & $0.9(0.1,5.6)$ \\
\hline Women who adopted a LARC & $n=35$ & $n=172$ & & $n=54$ & $n=68$ & & $n=24$ & $\mathrm{n}=\mathbf{2 8}$ & \\
\hline $\begin{array}{l}\text { 10. Told where to get implant/IUD } \\
\text { removed }\end{array}$ & 74.3 & 70.4 & $0.8(0.2,3.8)$ & 96.2 & 79.1 & $0.1(0.1,0.2)^{* * *}$ & 79.2 & 92.9 & $3.4(1.4,10.2)^{*}$ \\
\hline $\begin{array}{l}\text { 11. Told when to get implant/IUD } \\
\text { removed }\end{array}$ & 85.7 & 81.4 & $0.7(0.1,4.3)$ & 98.1 & 89.4 & $0.2(0.0,2.6)$ & 91.7 & 96.4 & $2.5(1.4,4.2)^{* * *}$ \\
\hline $\begin{array}{l}\text { 12. Told could have implant/IUD } \\
\text { removed whenever wanted }\end{array}$ & 77.1 & 76.7 & $1.0(0.1,6.7)$ & 84.9 & 68.7 & $0.4(0.1,1.3)$ & 83.3 & 96.4 & $5.4(0.6,51.6)$ \\
\hline $\begin{array}{l}\text { 13. Could correctly state when } \\
\text { implant or IUD would expire }\end{array}$ & 85.7 & 80.8 & $0.7(0.1,4.1)$ & 88.9 & 86.8 & $0.8(0.5,1.4)$ & 91.7 & 92.9 & $1.2(0.6,2.2)$ \\
\hline $\begin{array}{l}\text { FFIC LARC composite: Percentage } \\
\text { of women who adopted a LARC } \\
\text { responding positively to ALL indi- } \\
\text { cators } 3 \text { through } 13\end{array}$ & 37.1 & 15.7 & $0.3(0.1,1.8)$ & 40.7 & 26.4 & $0.5(0.3,0.8)^{* *}$ & 20.8 & 17.9 & $0.8(0.1,5.1)$ \\
\hline
\end{tabular}


TABLE 4. Continued

\begin{tabular}{|c|c|c|c|c|c|c|c|c|c|}
\hline Outcome & $\begin{array}{l}\text { Static } \\
(n=55) \\
\%\end{array}$ & $\begin{array}{l}\text { Outreach/ } \\
\text { Special FP Day } \\
(n=180) \\
\%\end{array}$ & $\begin{array}{l}\text { OR }(95 \% \mathrm{Cl})^{\mathrm{a}} \\
\text { or P Value }\end{array}$ & $\begin{array}{l}\text { Static } \\
(n=100) \\
\%\end{array}$ & $\begin{array}{l}\text { Outreach } \\
(n=100) \\
\%\end{array}$ & $\begin{array}{l}\text { OR } \\
(95 \% \mathrm{Cl})^{\mathrm{a}}\end{array}$ & $\begin{array}{l}\text { Static } \\
(n=90) \\
\%\end{array}$ & $\begin{array}{l}\text { Outreach } \\
(n=60) \\
\%\end{array}$ & $\begin{array}{l}\text { OR }(95 \% \mathrm{Cl})^{\mathrm{a}} \\
\text { or P Value }\end{array}$ \\
\hline \multicolumn{10}{|l|}{ FFIC mean score } \\
\hline $\begin{array}{l}\text { FFIC mean LARC score: Average } \\
\text { number of indicators } 3 \text { through } 13 \\
\text { for which response was positive } \\
\text { (highest possible score }=11 \text { ) } \\
\text { among women who adopted a } \\
\text { LARC }\end{array}$ & 8.5 & 8.3 & .70 & 9.8 & 8.7 & $.002^{* *}$ & 8.3 & 8.6 & .33 \\
\hline
\end{tabular}

Abbreviations: Cl, confidence interval; DRC, Democratic Republic of the Congo; FFIC, full, free, and informed choice; FP, family planning; IUD, intrauterine device; LARC, long-acting reversible contraception; $O R$, odds ratio.

* $P \leq .05 ;{ }^{* *} P \leq .01 ;{ }^{* * *} P \leq .001$

a Error estimates are adjusted for clustering by facility.

b $P$ values are reported for the FFIC mean scores at the end of the table.

ing all aspects of FFIC, including additional questions related to LARC, compared with $40.7 \%$ of clients of static services $(\mathrm{OR}=0.5 ; 95 \% \mathrm{CI}, 0.3$ to $0.8 ; P \leq .01)$. The directionality of differences in the DRC and Uganda was the same, but again, was not significant. The average number of FFIC elements, including LARC elements, for which the response was positive was between 8.3 and 9.8 (of 11) for all countries. The difference was again only significant in Tanzania (9.8 in static services, 8.7 in mobile outreach, $P \leq .01)$. Importantly, between $92.7 \%$ and $100 \%$ of clients who received a family planning method obtained their method of choice in all countries and modalities, and the large majority of clients $(74.0 \%$ to $97.9 \%)$ also reported that they made the decision to use family planning either by themselves or jointly with their partner or provider.

In the DRC, only 1 individual measure of FFIC-the client participating in family planning decision making-showed a significant difference between the service delivery approaches: $74.0 \%$ of clients of mobile outreach and special family planning days reported such joint decision making compared with $96.2 \%$ of clients of static services (OR=0.1; 95\% CI, 0.0 to $0.4 ; P \leq .001$ ) (Table 4 ). No other individual measures of FFIC were significant, and there was no clear trend in directionality among the indicators. However, there was a notable difference in the percentage of women who said that they were given a chance to ask questions: less than half $(48.3 \%)$ attending mobile outreach/special family planning days compared with $61.8 \%$ at static services. It should also be noted that although differences in the FFIC composite indicator were not significant, only 1 in 5 clients attending mobile outreach or special family planning days reported experiencing all measures of FFIC, compared with 1 in 2 clients at static services.

Similar to the DRC, most of the indicators of FFIC did not differ significantly by service delivery modality in Tanzania. The overall trend suggested that FFIC was better at static services compared with mobile outreach, with 3 individual indicators significantly so: reporting that the provider asked about their reproductive intentions $(\mathrm{OR}=0.2$; $95 \% \mathrm{CI}, 0.1$ to $0.7 ; P \leq .01)$, reporting that they were counseled on the method received $(\mathrm{OR}=0.5$; $95 \% \mathrm{CI}, 0.4$ to $0.6 ; P \leq .001)$, and reporting that they were told where to have their implant or IUD (OR $=0.1 ; 95 \% \mathrm{CI}, 0.1$ to $0.2 ; P \leq .001)$. Other elements of counseling, such as "counseled on side effects of method received" and "told could have implant/IUD removed whenever wanted" differed

\author{
Most family \\ planning clients \\ obtained their \\ method of choice \\ in all countries \\ and service \\ modalities.
}


TABLE 5. Proportion of Clients Reporting Being "Very Satisfied" With Aspects of Services, by Country and Service Delivery Modality

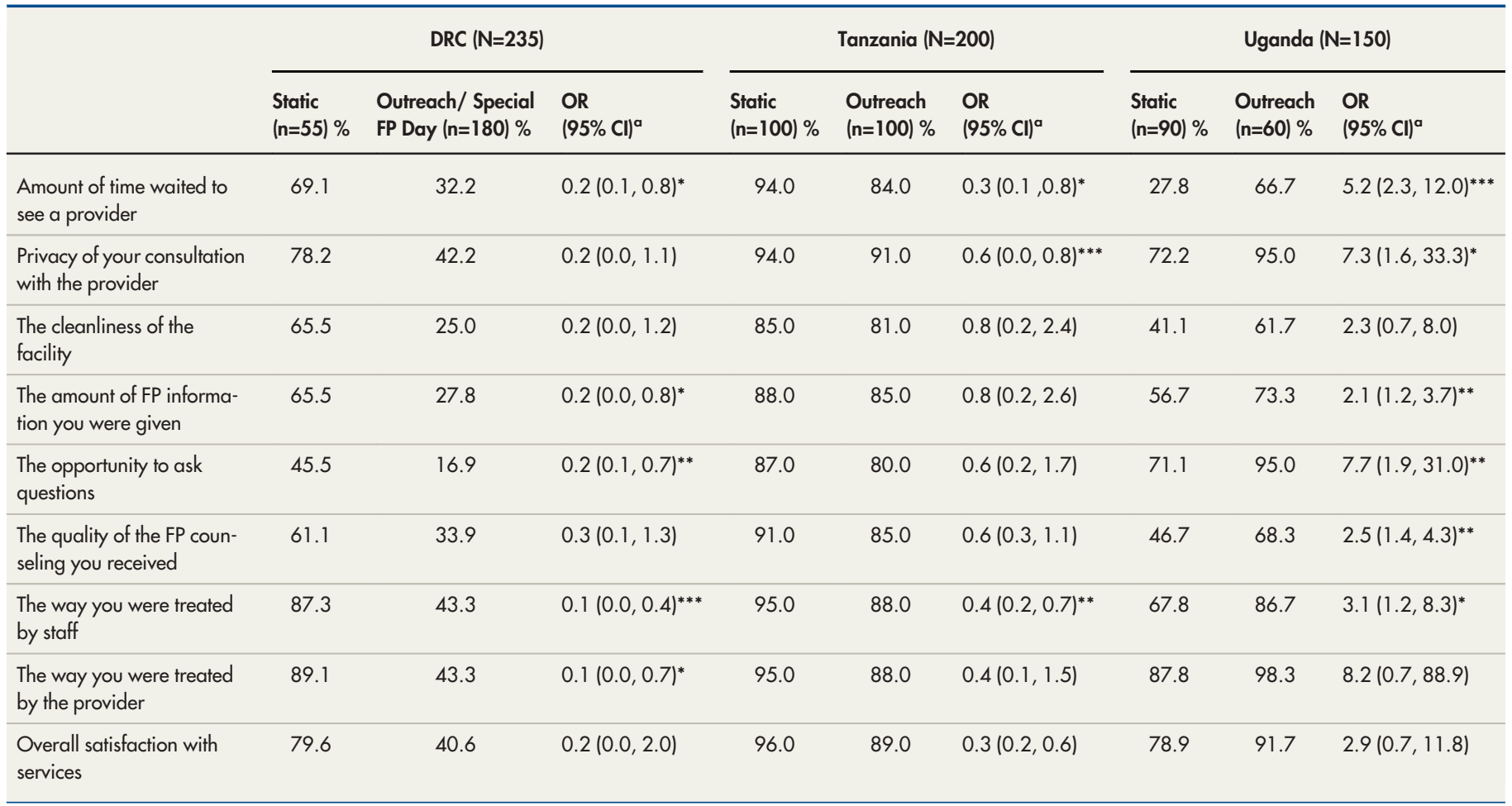

Abbreviations: $\mathrm{Cl}$, confidence interval; DRC, Democratic Republic of the Congo; FP, family planning; OR, odds ratio.

${ }^{*} P \leq .05 ;{ }^{* *} P \leq .01 ;{ }^{* * *} P \leq .001$

a Error estimates are adjusted for clustering by facility.

between the 2 service delivery modalities but did not reach the level of statistical significance.

In Uganda, only 2 indicators-told where, and when, to get an IUD/implant removed-showed significant differences, both among LARC adopters. Both suggested superior counseling at mobile outreach compared with static services, in contrast to Tanzania (Table 4). Overall, where there were sizable differences between the 2 service delivery modalities on indicators that did not rise to the level of statistical significance, most measures of FFIC were better for mobile outreach services.

We did not make any statistical comparisons among the countries because their family planning programs are in different stages of development, and there were likely differences between populations served. However, we observed that in Tanzania, the absolute value of most indicators of FFIC was over $80 \%$ (Table 4 ). In contrast, many values in Uganda and the DRC were much lower, while variability among different measures was high. In the DRC, measures ranged from $48.3 \%$ for being given a chance to ask questions at outreach services/special family planning day events to $100 \%$ for obtained method of choice at static services. In Uganda, the measures ranged from $26.7 \%$ for provider discussed 3 or more methods at static services to $97.6 \%$ for obtained method of choice at static services.

\section{Satisfaction}

Although overall satisfaction did not differ statistically by mode of service delivery in the DRC, significantly lower percentages of respondents attending outreach services/special family planning days than those at static services reported being "very satisfied" for 5 of the 8 individual measures of satisfaction: amount of time waited, amount of family planning information given, the opportunity to ask questions, the way the client was treated by staff, and the way she was treated by the provider (Table 5). For the remaining measures, the trend was the same, although not statistically significant. 
In Tanzania, lower percentages of mobile outreach clients than static service clients also reported satisfaction with aspects of services, with 3 measures significantly so: amount of time waited, privacy of consultation, and the way the client was treated by staff (Table 5).

Although overall satisfaction did not differ statistically by mode of service delivery in Uganda, significantly higher percentages of respondents attending outreach services/special family planning days than those at static services reported being "very satisfied" on 6 of the 8 individual measures of satisfaction: amount of time waited, privacy of consultation, amount of family planning information given, opportunity to ask questions, and quality of family planning counseling received, and the way the client was treated by staff (Table 5).

As stated earlier, statistical comparisons were not made among the countries. Nevertheless, it is notable that the proportion of clients reporting being very satisfied in the DRC varied widely, from just $16.9 \%$ of women attending mobile outreach services/special family planning days for the opportunity to ask questions and $25.0 \%$ for facility cleanliness to $89.1 \%$ at static services for treatment by the provider (Table 5). In Uganda, there was also pronounced variation, with just over a quarter $(27.8 \%)$ of clients at static services being very satisfied with the amount of time they waited to nearly all $(98.3 \%)$ clients at mobile outreach services being very satisfied with the way they were treated by the provider. In contrast, at least $80 \%$ of clients reported being very satisfied on every measure in Tanzania.

\section{DISCUSSION}

The analysis of the composite FFIC indicator suggests that, overall, clients experienced greater FFIC at static services compared with mobile outreach in Tanzania, while significant differences were not found in the DRC or Uganda. Although fewer than half of clients reported experiencing all aspects of FFIC in all countries and for all modalities, the FFIC mean score indicates that clients-all family planning adopters and LARConly adopters-experienced the majority of elements of FFIC. The fact that few of the individual indicators of FFIC were significant in any country but showed greater differences when examined as a composite indicator may be an issue of power. It is, therefore, important to look at trends in the domains of FFIC as well as the composite measure and mean score.
The results indicate that women were equally likely to obtain a family planning method and, specifically, the method they wanted at all service delivery modalities in each country. It is important to note that a higher percentage of women who came to non-static service sites had a preexisting preference for a LARC than those attending static services in all 3 countries. Women coming to nonstatic services may have sought those services specifically because they knew these methods would be available, thereby potentially masking a difference in method availability between service delivery modalities. The women's preference for LARCs at mobile outreach and special family planning days suggests that the high levels of implant uptake at these services were likely related primarily to preexisting preferences, rather than the unavailability of other methods or provider bias. In particular, in the DRC, the fact that methods were free during special family planning days and mobile outreach may have attracted clients who were waiting specifically for free events in order to obtain LARCs, which are normally costly.

Findings for the other individual indicators of FFIC were mixed. One indicator showed better performance at static services in the DRC; 3 indicators showed better performance at static services in Tanzania; and 2 indicators showed better performance at mobile outreach in Uganda. In Tanzania, the better performance of static services may be a product of the lower volume of clients compared with mobile outreach, resulting in longer counseling sessions. However, we did not measure the length of counseling sessions for each client and, therefore, cannot be certain of this interpretation. In Uganda, the indicators with better results for mobile outreach services were all related to LARCs, possibly reflecting that providers who routinely participate in mobile outreach events are more skilled in the provision of and counseling for LARCs. However, the mobile outreach model in Tanzania and Uganda was similar; therefore, one would expect similar outcomes. It is also plausible that when a client arrives having already decided on a method-which was more likely for non-static services in all countriesproviders are less likely to give full counseling, assuming-perhaps incorrectly - that the client has all the information she needs. In the DRC, there was no clear trend, indicating that clients at all modalities were equally likely to experience aspects of FFIC. Facilities that provided static services received more routine support and supervision than facilities that held mobile outreach, 
which may have affected outcomes as well, though the pattern of impact is not clear.

Questions on counseling specifically asked whether "the provider" counseled the client about a particular element. Group counseling is common at mobile outreach services and special family planning day events. It is possible that some clients responded "no" to some elements of counseling because they received information from a different staff member, not the provider who gave her the method. This may have contributed to the low number of clients at both service delivery modalities in Uganda who stated that the provider discussed 3 or more methods with them and that the provider counseled them on the method they received. It is common for a provider to review the array of methods available during group counseling, whereas the accepted method may be given by a different provider. A more nuanced questionnaire could inform this understanding of the data.

Clients attending mobile outreach and special days tended to be of lower SES and education level. It is possible that women of lower SES might not understand all of the information during counseling, which, in turn, may have affected their reporting of FFIC. In practice, it is not possible to separate the service delivery modality from the profile of client reached. It is therefore important to consider how the client profile may affect FFIC in addition to the service delivery modality.

It is essential to note that even when differen-

Across all modalities, clients were often not counseled on potential side effects or given the opportunity to ask the provider questions. ces between service delivery modalities were not found, some of the indicators of FFIC should be improved in all countries and for all modalities. For example, at least one-quarter of clients in each country and for each service delivery modality reported that they were not counseled on potential method side effects. In some cases, this result may have been because a client was a continuing user of a method; however, it is important to ensure that all clients are given accurate information about their method options and the benefits and risks of family planning. This is particularly true when examining whether clients were given a chance to ask questions. Although there were no significant differences between modalities in any country, Uganda was the only country where more than three-quarters of clients at any modality reported being able to ask questions. All clients should have the opportunity to ask questions. Despite this, nearly all clients received their method of choice, the large majority of clients reported independent or joint decision making, and there was no indication that any client rights were violated. More research is needed to understand why clients may not be experiencing all aspects of FFIC and how to better support providers to deliver quality counseling in various service delivery modalities.

Indicators of satisfaction appeared to align with indicators of FFIC; that is, in the modality where clients reported superior indicators of FFIC, they were also more likely to be very satisfied with various aspects of services and counseling. Overall, this indicates that ensuring that clients experience FFIC may increase client satisfaction with services, though specific analysis of any such correlation would be needed to investigate this concept. Further, some elements of services that may affect satisfaction, such as wait time, are beyond FFIC and not likely to be correlated. The proportion of women reporting being very satisfied with a variety of individual indices was notably low in both service delivery modalities in the DRC and Uganda, suggesting that improvements could be made to all services.

Although no statistical comparisons were made among countries, the relatively lower experiences of elements of FFIC and of satisfaction in the DRC and Uganda compared with Tanzania is notable. It is not possible to extrapolate from these data why this difference occurred; however, the prevalence of family planning services, the maturity of the family planning programs, the funding and political environment, and other external factors may have affected providers' abilities to deliver quality services. The implementation of the ExpandFP program also differed from country to country, with varying numbers of providers trained in family planning counseling, a different reach of the program, and slightly different models for mobile outreach and special family planning days. These environmental factors may also affect clients' expectations and experiences with family planning services.

The differences seen in client characteristics between women attending mobile outreach or special family planning days compared with those at static services are also important to consider in terms of the populations reached in the 3 countries. Findings indicate that, overall, mobile outreach and special family planning day services reached women of lower SES than static services, thus underscoring the importance of non-static service delivery options in reaching more disadvantaged and vulnerable populations. The lower proportion of women with a history of modern family planning use also indicates that mobile outreach and special family planning days may reach clients with a long-standing 
unmet need, particularly an unmet need for limiting childbearing. These differences in characteristics indicate that mobile outreach and special family planning days are important strategies for increasing access to family planning. Moreover, the higher comparative uptake of LARC by women attending mobile outreach and special family planning days, and the possibility that many women came to these services with these methods already in mind, indicate that non-static services are important ways to increase access to these underutilized methods for underserved populations. The women's SES may have also affected how providers counseled them and/or how the clients experienced, understood, and recalled that counseling.

Further research is needed to explore the reasons for differences in FFIC and to determine what approaches may effectively ensure that providers enable all clients, especially women of lower SES, to make FFIC. It is equally important to ensure that the various service delivery modes, including those crucial to reaching underserved populations with underutilized methods, expand access to family planning while offering quality counseling and FFIC for all clients. Existing tools that can be used to monitor and improve clients' experiences of FFIC can and should be brought to scale at national levels-across the private, public, and non-profit spheres-and used to continually improve services. Additionally, client-provider interactions can and should be tailored to meet individual client needs: some clients may want more information than others, returning clients may be happy with their method and not need or want counseling on other methods, while others may want to hear about an array of options. Qualitative research on both the client and provider experiences with counseling can help program planners and implementers to better understand these dynamics and how to measure them. Observations of client-provider interactions are also important to understand the reasons why some clients had better experiences with some elements of FFIC than others.

\section{Limitations}

This research is not generalizable at the country level because the facilities, which were purposively selected in each country, received different levels of project support and, therefore, are not representative of facilities in general. Similarly, public-sector mobile outreach may differ from private-sector or NGO-led outreach, which was not captured here, and the client profile at study facilities may not be representative of clients, in general. Additionally, the study's findings are dependent on client recall of experiences. Recall bias was minimized by interviewing clients immediately following their receipt of services and prior to their exit from the facility. This was a strength of our study design, compared to household surveys, which interview clients about counseling practices long after the event has occurred. Courtesy bias may also have affected the reliability of study results, especially related to measures of satisfaction. This bias was minimized by interviewing clients privately and by nonfacility staff conducting the interviews. In addition, measures of the elements of FFIC were limited in our study to the client's perspective. Finally, the relatively small sample size may have limited the power to detect significant differences, in particular, because the desired sample size was not reached in all modalities.

\section{CONCLUSIONS}

The study findings suggest that client experiences of FFIC elements varied among the service delivery modalities, with certain elements scoring lower, and other elements scoring higher, at some nonstatic service delivery modalities compared with static services. The reasons for this variance may be related to client volume during non-static service delivery events, the profile of clients who attended non-static service delivery, differences in how providers approached women of higher or lower SES, or other unknown factors. In cases where the FFIC scores were lower, provider monitoring, supervision, and follow up on appropriate counseling methods as well as ensuring sufficient staff time for comprehensive counseling may have enhanced clients' satisfaction and experiences of FFIC. Implementers may need to increase staffing, establish a maximum number of clients during special family planning events, or use other approaches to ensure enough time for counseling. Further research is needed to understand the conditions or circumstances that may make FFIC more difficult in mobile outreach settings or during special family planning days. Special family planning days and mobile outreach days play a key part in expanding access to family planning, and the large majority of clients were able to obtain the method of their choice in these events, the majority of whom chose a LARC. Each service delivery modality poses different challenges to providers to provide quality services and counseling, and these must be accounted for in program planning.

\author{
Using various \\ service delivery \\ modes is crucial to \\ reaching \\ underserved \\ populations with \\ underutilized \\ methods and \\ expanding access \\ to family \\ planning.
}


Despite some high scores, most elements of FFIC for all service delivery modalities and in all countries still showed room for improvement. Women who adopt family planning should receive high-quality care, including FFIC. This study shows the importance of monitoring FFIC as programs expand access to family planning services and methods. It is not enough to reach clients with methods and services, clients should be empowered to make decisions fully, freely, and with correct and complete information.

Acknowledgments: The authors wish to express thanks to Megan Schmitt and Alison Ellis for their helpful comments on earlier drafts of this article and to Elizabeth Jackson and Gwyneth Vance for supporting data analysis. We would also like to thank Claudine Monganza, Robert Mwamba, Simon Ndizeye, Samuel Kakembo, Chloe Manchester, and Edwin Ernest for assistance with study implementation in the 3 countries. Thanks to the Bill \& Melinda Gates Foundation for funding this study.

Funding: Bill \& Melinda Gates Foundation.

Competing Interests: None declared.

\section{REFERENCES}

1. Curry DW, Rattan J, Huang S, Noznesky E. Delivering high-quality family planning services in crisis-affected settings II: results. Glob Health Sci Pract. 2015;3(1):25-33. CrossRef. Medline

2. Daly C, Wickstrom J, Jarvis L, Schmitt M. Increasing Family Planning Capacity, Access, and Quality: Results from EngenderHealth's ExpandFP Project in Tanzania. New York: EngenderHealth; 2016. https://www.engenderhealth.org/files/pubs/project/expandfp/ Expand-FP-Tanzania-Brief.pdf. Accessed July 13, 2018.

3. Duvall S, Thurston S, Weinberger M, Nuccio O, Fuchs-Montgomery N. Scaling up delivery of contraceptive implants in sub-Saharan Africa: operational experiences of Marie Stopes International. Glob Health Sci Pract. 2014;2(1):72-92. CrossRef. Medline

4. Jacobstein R. Lessons from the recent rise in use of female sterilization in Malawi. Stud Fam Plann. 2013;44(1):85-95. CrossRef. Medline

5. Jacobstein R, Stanley H. Contraceptive implants: providing better choice to meet growing family planning demand. Glob Health Sci Pract. 2013;1(1):11-17. CrossRef

6. Marie Stopes International (MSI). Scaling Up FP Access and Choice through MSI Mobile Outreach: Results and Insights from the SIFPO Project. London: MSI; 2015.

7. Ngo TD, Nuccio O, Reiss K, Pereira SK. Expanding Long-acting and Permanent Contraceptive Use in Sub-Saharan Africa to Meet FP2020 Goals. London: Marie Stopes International; 2013. https:// mariestopes.org/resources/expanding-long-acting-and-permanentcontraceptive-use-in-sub-saharan-africa-to-meet-fp2020-goals/. Accessed July 13, 2018.

8. Asnake M, Henry EG, Tilahun Y, Oliveras E. Addressing unmet need for long-acting family planning in Ethiopia: Uptake of single-rod progestogen contraceptive implants (Implanon) and characteristics of users. Int J Gynaecol Obstet. 2013;123(suppl 1):e29-e32. CrossRef. Medline

9. Jacobstein R, Curtis C, Spieler J, Radloff S. Meeting the need for modern contraception: effective solutions to a pressing global challenge. Int J Gynaecol Obstet. 2013;121(suppl 1):S9-S15. CrossRef. Medline

10. Marie Stopes International. Global Impact Report 2012: Reaching the Under-served. London: Marie Stopes International; 2013. https://mariestopes.org/media/2164/global-impact-report2012-reaching-the-under-served.pdf. Accessed July 13, 2018.

11. Dassah ET, Odoi AT, Owusu-Asubonteng G. Prevalence and factors predictive of long-acting reversible contraceptive use in a tertiary hospital in urban Ghana. Eur J Contracept Reprod Health Care. 2013;18(4):293-299. CrossRef. Medline

12. Family Planning 2020 (FP2020), United Nations Foundation. FP2020 Commitment to Action: Measurement Annex. Washington, D.C: FP2020/United Nations Foundation; 2015. http://20142015progress.familyplanning2020.org/uploads/15/03/FP2020_ MeasurementAnnex_2015_Spreads.pdf. Accessed July 13, 2018.

13. Gebremariam A, Addissie A. Intention to use long acting and permanent contraceptive methods and factors affecting it among married women in Adigrat town, Tigray, Northern Ethiopia. Reprod Health. 2014;1 1(1):24. CrossRef. Medline

14. Hubacher D, Mavranezouli I, McGinn E. Unintended pregnancy in sub-Saharan Africa: magnitude of the problem and potential role of contraceptive implants to alleviate it. Contraception. 2008;78 (1):73-78. CrossRef. Medline

15. Neukom J, Chilambwe J, Mkandawire J, Mbewe RK, Hubacher D. Dedicated providers of long-acting reversible contraception: new approach in Zambia. Contraception. 2011;83(5):447-452. CrossRef. Medline

16. Shabiby MM, Karanja JG, Odawa F, et al. Factors influencing uptake of contraceptive implants in the immediate postpartum period among HIV infected and uninfected women at two Kenyan District Hospitals. BMC Womens Health. 2015;15(1):62. CrossRef. Medline

17. Family Planning 2020. Commitments. Family Planning 2020 Web site. http://www.familyplanning2020.org/commitments. Accessed November 15, 2016.

18. Family Planning 2020. Revitalized Commitments. Family Planning 2020 Web site. http://summit2017.familyplanning2020.org/ revitalized-commitments.html\#Uganda. Accessed July 25, 2017.

19. Family Planning 2020. About Us. Family Planning 2020 Web site. hitp:// unw.familyplanning2020.org/about. Accessed November 15, 2016.

20. Performance Monitoring and Accountability (PMA2020). PMA2015/Kinshasa-R3: Performance, Monitoring \& Accountability 2020. Baltimore: PMA2020. http://pma2020.org/sites/default/ files/DRCR3-EN-FP-Brief-v6.2015.10.12.pdf. Accessed June 10, 2016.

21. Uganda Bureau of Statistics (UBOS) and ICF International Inc. Uganda Demographic and Health Survey 2011. Kampala, Uganda: UBOS and Calverton, Maryland: ICF International Inc.; 2012. https://dhsprogram.com/pubs/pdf/fr264/fr264.pdf. Accessed July 13, 2018

22. Uganda Bureau of Statistics (UBOS) and ICF. Uganda Demographic and Health Survey 2016: Key Indicators Report. Kampala, Uganda: UBOS, and Rockville, Maryland, USA: UBOS and ICF; 2017. https://www.ubos.org/onlinefiles/uploads/ubos/pdf\% 20documents/Uganda_DHS_2016_KIR.pdf. Accessed July 13, 2018.

23. Ministry of Health, Community Development, Gender, Elderly and Children (MOHCDGEC), [Tanzania Mainland], Ministry of Health (MOH) [Zanzibar], National Bureau of Statistics (NBS), Office of the Chief Government Statistician (OCGS), and ICF International. Tanzania Demographic and Health Survey and Malaria Indicator Survey 2015-16. Dar es Salaam, Tanzania and Rockville, Maryland, USA: MOHSW, MOH, NBS, OCGS, and ICF International; 2016. https://dhsprogram.com/pubs/pdf/fr321/fr321.pdf. Accessed July 13, 2018

24. National Bureau of Statistics (NBS) and ICF Macro. Tanzania Demographic and Health Survey 2010. Dar es Salaam, Tanzania: NBS and ICF Macro; 2011. https://dhsprogram.com/pubs/pdf/ FR243/FR243\%5B24June2011\%5D.pdf. Accessed July 13, 2018. 
25. Hardee K, Harris S, Rodriguez M, et al. Achieving the goal of the London Summit on Family Planning by adhering to voluntary, rightsbased family planning: what can we learn from past experiences with coercion? Int Perspect Sex Reprod Health. 2014;40(04):206214. CrossRef. Medline

26. Hardee K, Kumar J, Newman K, et al. Voluntary, human rightsbased family planning: a conceptual framework. Stud Fam Plann. 2014;45(1):1-18. CrossRef. Medline

27. The RESPOND Project. Checkpoints for Choice: An Orientation and Resource Package. New York, NY: EngenderHealth, The RESPOND Project; 2014. http://www.engenderhealth.org/files/pubs/familyplanning/Checkpoints-for-Choice-An-Orientation-and-ResourcePackage.pdf. Accessed July 13, 2018.

28. EngenderHealth. Advancing Family Planning Use and Building Local Capacity in Three Countries of Sub-Saharan Africa: Results from EngenderHealth's ExpandFP Project. New York: EngenderHealth; 2015.
29. Hutchinson PL, Do M, Agha S. Measuring client satisfaction and the quality of family planning services: a comparative analysis of public and private health facilities in Tanzania, Kenya and Ghana. BMC Health Serv Res. 2011;11(1):203. CrossRef. Medline

30. Costello M, Lacuesta M, RamaRao S, Jain A. A client-centered approach to family planning: the Davao project. Stud Fam Plann. 2001;32(4):302-314. CrossRef. Medline

31. Kamhawi S, Underwood C, Murad H, Jabre B. Client-centered counseling improves client satisfaction with family planning visits: evidence from Irbid, Jordan. Glob Health Sci Pract. 2013;1 (2):180192. CrossRef. Medline

32. Kumar J, Bakamiian L, Connor H, Harris S. Voluntary Family Planning Programs That Respect, Protect, and Fulfill Human Rights: A Systematic Review of Tools. Washington, DC: Futures Group and EngenderHealth; 2014. http://www.respond-project.org/archive/ files/1/1.1/1.1.4/Voluntary-FP-Programs-Review-Tools.pdf. Accessed July 13, 2018.

\section{En français}

Perceptions des clients concernant la qualité et le choix au sein des services statiques, mobiles et lors des journées planification familiale dans 3 pays africains

Dans les 3 pays, quasiment toutes les femmes ont obtenu la méthode de leur choix, sachant que davantage de clientes des services de sensibilisation mobile et des journées spéciales planification familiale avaient auparavant une préférence pour les implants, par rapport aux clientes des services statiques. Les clientes des différents types de service ont déclaré avoir bénéficié de la plupart des éléments du choix total, libre et éclairé, certains aspects peuvent néanmoins être améliorés, comme par exemple les conseils relatifs aux éventuels effets secondaires et le fait de permettre aux clientes de poser des questions.

\section{RÉSUMÉ}

Contexte : L'utilisation de méthodes réversibles de longue durée d'action a considérablement augmenté en République démocratique du Congo (RDC), en Tanzanie et en Ouganda. L'adoption des méthodes réversibles de longue durée d'action est particulièrement élevée pendant les campagnes de sensibilisation mobile et les journées spéciales planification familiale. Il conviendrait donc d'examiner les perceptions des clientes et leur expérience en matière de choix total, libre et éclairé dans différentes modalités de prestation de services.

Méthodes : Entre avril et juillet 2015, nous avons conduit une enquête transversale auprès des clientes de planification familiale pour évaluer le choix total, libre et éclairé et la satisfaction des clientes par rapport aux services statiques, mobiles et lors des journées spéciales planification familiale en RDC $(n=9$ sites), Tanzanie $(n=13)$, et Ouganda $(n=8)$. Cette étude a permis de mener des recherches sur les perceptions des clientes eu égard aux 13 éléments du choix total, libre et éclairé notamment la mesure de la qualité des conseils et de la satisfaction des personnes interviewées à propos des différentes approches en matière de prestation de service. Les résultats composites du choix total, libre et éclairé ont été interprétés et analysés comme correspondant au pourcentage de femmes qui ont répondu par l'affirmative à l'ensemble des éléments et au score moyen de réponses positives. La satisfaction a été évaluée en utilisant une échelle de Likert de 4 points. Nous avons eu recours à la régression logistique pour évaluer le lien entre les résultats primaires et le mode de prestation de service.

Résultats : Au total, nous avons interviewé 585 femmes ( $n=150$ en Ouganda, $n=200$ en Tanzanie, et $n=235$ en RDC). La grande majorité des clientes de tous les pays et de l'ensemble des modalités ont obtenu la méthode de leur choix. Comparées aux clientes de services statiques les clientes des services mobiles et des journées spéciales planification familiale ont préféré des méthodes réversibles de longue durée d'action et des méthodes permanentes, en particulier les implants. Les mesures composites du choix total, libre et éclairé étaient plus faibles pour la sensibilisation mobile que pour les services statiques en Tanzanie parmi l'ensemble des clientes de planification familiale (coefficient de probabilité $[C P]=0,5 ; P \leq, 001$ ) et parmi celles qui utilisent des méthodes réversibles de longue durée d'action en particulier $(C P=0,5 ; P \leq, 01)$; aucune différence majeure n'a été constatée en RDC ou en Ouganda. Un score moyen du choix total, libre et éclairé parmi toutes les clientes de services de planification familiale a montré que les clientes de l'ensemble des modalités de tous les pays avaient signalé avoir bénéficié de la plupart des éléments du choix total, libre et éclairé avec des moyennes variant entre 4,8 et 6,1 des 7 éléments. Pour ce qui est des clientes de méthodes réversibles de longue durée d'action en particulier, les scores moyens allaient de 8,3 à 9,8 des 11 éléments. Lorsqu'un pourcentage plus élevé de clientes ont bénéficié d'un degré important de choix total, libre et éclairé, une proportion plus importante de clientes ont également eu tendance à signaler être " très satisfaites » des différents aspects de services et conseils.

Conclusions : Les résultats indiquent que les journées spéciales de planification familiale et les services de sensibilisation constituent des moyens importants et viables pour accroître l'accès aux services de planification familiale, notamment aux méthodes réversibles de longue durée d'action, mais il faut accorder une plus grande attention au respect et à la réalisation du choix total, libre et éclairé des clientes dans l'ensemble des modalités de prestation de service.

\section{Peer Reviewed}

Received: January 23, 2018; Accepted: June 20, 2018

Cite this article as: Jarvis L, Wickstrom J, Shannon C. Client perceptions of quality and choice at static, mobile outreach, and special family planning day services in 3 African countries. Glob Health Sci Pract. 2018;6(3):439-455. hitps://doi.org/10.9745/GHSP-D-18-00047

( ) Jarvis et al. This is an open-access article distributed under the terms of the Creative Commons Attribution 4.0 International License (CC BY 4.0), which permits unrestricted use, distribution, and reproduction in any medium, provided the original author and source are properly cited. To view a copy of the license, visit http:// creativecommons.org/licenses/by/4.0/. When linking to this article, please use the following permanent link: https:// doi.org/10.9745/GHSP-D-18-00047 